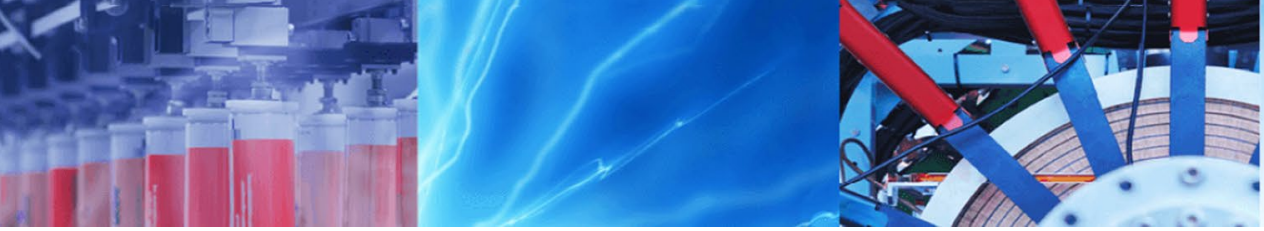

Research Article

\title{
Optimization of light-dependent resistor sensor for the application of solar energy tracking system
}

\author{
Venkatarao Dadi ${ }^{1}$ D . Swapna Peravali ${ }^{1}$
}

Received: 21 March 2020 / Accepted: 4 August 2020 / Published online: 11 August 2020

(c) Springer Nature Switzerland AG 2020

\begin{abstract}
Optimization of cadmium sulfide light-dependent resistor (CdS-LDR) sensor is one of the suitable circuit elements to be used as the sun-pointing sensor. The sun-pointing sensor is used in solar energy tracking systems to capture maximum power by photovoltaic (PV) cells or systems at the time of uniform or partial irradiance of the sun and effect of shade during clouds. PV cells or modules' generating power is affected due to partial shading. The PV cells are able to produce maximum power, as long as the sun's irradiance is projected perpendicular to the panel's surface. Optimization of lightdependent resistor CdS-LDR sensor is designed based on the intensity of the sun. A relation is obtained between intensity and photo-resistance of CdS-LDR sensor with coefficient of regression $\left(R^{2}\right)$ value of 0.99 . Maximum intensity of the sun is captured using CdS-LDR sensor which is designed with characteristic curve of intensity and photo-resistance using power algorithm. Minimum dull intensity of the sunlight is used to place the panel in initial position. In addition to that cloud effects with sudden transients are also analyzed using temperature humidity index term. The power gained by optimized dual axis solar tracking (DAST) system is $50.63 \%$ with reference to fixed panel. The generated power of DAST system is also analyzed under shading effect of cloud. Data are collected for every 2-3 s of time interval from 6:32:00 to 17:38:33 using real-time virtual instrumentation Parallax Data Acquisition tool.
\end{abstract}

Keywords Power algorithm · Light-dependent resistor · Minimum dull intensity of the sunlight (MDISL) · Mapping technique $\cdot$ Parallax Data Acquisition (PLX-DAQ) tool $\cdot$ Regression analysis

\section{Introduction}

Renewable energy resources like solar energy and its great demand of usage in electricity is drastically increased, whereas usage of nonrenewable sources like fossil fuel, coal and their demand in electricity is decreasing day by day due to their depletion and polluting nature. Partial shading of PV cells due to nonuniform irradiance significantly decreases the power delivered by the solar panel, because PV module cells are connected in series. In such a case the unshaded cells force a large current through the shaded ones, in the long term these hot spots reduce the life span of the module. In photovoltaic array systems partial shading or nonuniform irradiance is reduced using maximum power point tracking technique (MPPT). Dynamic and static $P V$ array reconfiguration techniques are used for reduction in partial shading effect for large PV plants. The efficiency of solar panel is significantly affected when the panel is installed nearer to large buildings or hills, at the time of sunrise or sunset or cloud effect due to nonuniform irradiance projected over the panel. Partial shading effect is minimized by direct sensing of irradiance or intensity parameter fall on the PV module in solar tracking systems [1].

Optimized sun-pointing sensor with tracking control parameter increases the tracking accuracy of the sun in

Venkatarao Dadi, dadivenkatarao@gmail.com; Swapna Peravali, peravali_r2000@yahoo.co.in|' Instrument Technology, AU college of Engineering, A.U., Visakhapatnam, Andhra Pradesh 530003, India. 
DAST applications. So captured power is increased include and exclude cloud effects, sunrise and sunset. Existing sun-pointing sensors with tracking control parameters used in solar tracking applications [2] such as photosensitive sensor is operated with differences of currents of photodetector [3], four quadrant LDRs are isolating the light from each LDR and sun position is measured by resistance sensitive comparison method [4], optimal azimuth and tilt angles of the sun measurement based on brightness and shade of the sun [5], measurement of the sun position using difference of voltages by means of comparator with four quadrant LDR [6], a design consists of two photodiodes and a metal wall creates light, shadow and differences of currents [7], four monolithic photodiodes with a transimpedence amplifier are used to measure elevation angle of the sun based on difference in voltage of the photodiodes [8], maximum light detection sensor applied in solar energy generation [9], and power of photo-diode sensor [10].

Tracking control parameters are designed to capture maximum irradiance in solar tracking applications such as analog signal of three LDRs arranged in tetrahedron [11], voltage difference of LDR sensors for single direction tracking systems [12], analog voltage of LDR with optimized series connected load resistance $\left(R_{\mathrm{L}}\right)$ [13], digital value of LDR sensor along with real-time virtual instrumentation test bench tool [14], and photo-resistance $\left(R_{\text {ph }}\right)$ of LDR sensor in terms of voltage [15].

Tracking control parameter implemented with LDR sensor interfaced to microcontroller is used to improve the power gain in DAST system. $29.58 \%$ power is gained using voltage as control parameter with LDR sensor interfaced to AVR microcontroller [16]. 30-40\% power is gained using voltage as control parameter with LDR sensor interfaced to PLC [17]. 28.04\% power is gained using analog signal as control parameter with LDR sensor interfaced to AVR [18]. $25-30 \%$ power is gained using voltage as control parameter with LDR sensor interfaced to ATmega (Arduino based) [15]. 30-40\% power is gained using voltage as control parameter with LDR sensor interfaced to ATmega (Arduino based) [19]. 36.25\% power is gained using analog signal as control parameter with LDR sensor interfaced to ATmega (Arduino based) [13].

It is identified that previous works do not considered the influence of actual solar intensity measurement as control parameter using LDR sensor in improving tracking accuracy. There is no evidence of optimization of CdS-LDR sensor for DAST systems from the literature.

This article is focus on analyzing DAST system performance in terms of power gain using optimized CdS-LDR sensor. During the time of partial shading or cloudy condition increase in tracking accuracy using optimized CdSLDR sensor is analyzed with clear condition. It is analyzed with increase in percentage of generated out power of DAST system with respect to theoretically calculated values.

Optimization of LDR sensor increases the power gain of DAST system during normal or nonuniform irradiance conditions. Light intensity comparison method is proposed to track the sun position using optimized CdS-LDR sensor. Correlation of CdS-LDR sensor characteristics described by manufacturer with real-time outside conditions is the major factor. Optimized CdS LDR sensor is obtained using characteristic curve of $R_{\mathrm{ph}}$ and intensity of the CdS-LDR sensor along with tracking mechanism. An application is implemented on DAST system which is designed with comparison of intensity of the sun measured by optimized CdS LDR sensor segment.

In this proposed work $50.63 \%$ power is gained using light intensity as control parameter with LDR sensor interfaced to ATmega (Arduino based). Also, identified that DAST system if not positioned to initial position leads to some generating power loss by solar panel which is resolved by minimum dull intensity of the sunlight (MDISL) using optimized CdS-LDR sensor. During the time of cloudy, one more parameter is observed that is sudden high power impulse (surge power) with reference to temperature humidity index (THI) term which is used to identify cloud release and effect condition of the sunlight.

\section{Methodology}

With power algorithm, LDR sensor plays major role in the measurement of the sun intensity, tracking and minimum dull intensity of the sunlight (MDISL).

Intensity parameter of optimized LDR sensor is used to find the following aspects (i) to track the sun position perpendicularly, (ii) to track the maximum intensity of the sunlight during the time of shading effect.

MDISL is used to operate the tracking mechanism in various conditions such as (a) to stop or run the tracking motors by microcontroller under cloud effect, (b) move to initial position of tracking system when there is no sun's irradiance for more than $8 \mathrm{~h}$ or above.

Sudden high power impulses along with THI (Temperature and humidity) are used to find the switching of cloud such as (1) cloud released, (2) cloud effect, (3) immediate switching between cloud release \& effect, and vice versa.

\subsection{Design of CdS LDR sensor intensity and its optimization}

Light absorption wavelength range of CdS-LDR is 350-850 nanometer $(\mathrm{nm})$ which is compatible with the highest electromagnetic radiation emitted by the sun 
range of $400-800 \mathrm{~nm}$. Optimization of LDR sensor is designed from characteristic curve of $R_{\text {ph }}$ with the intensity in terms of lux ( $\left(\mathrm{nt}_{\mathrm{lx}}\right)$ of $5 \mathrm{~mm}$ CdS LDR specification data sheet. Data samples are chosen at mid points of LDR sensor characteristic curve of the intensity and $R_{\mathrm{ph}}$ as show in Table 1.

Curve fitting is used to design the intensity equation using scattered points and data trend line analysis in excel $[20,21]$. Data samples are correlated using power algorithm which has $R^{2}$ value of 0.995 as shown in Fig. 1.

LDR sensor can be connected with power supply $\left(V_{s}\right)$ and load resistance $\left(R_{\mathrm{L}}\right)$ in two ways as shown in Fig. 2a, b, where both the connections are negative intensity coefficient types.

ATmega 328P microcontroller which has 10 bit ADC which converts measured LDR sensor output into analog value (digital) in the range of $0-1023$ such as analogRead $R_{\mathrm{L}}$ (anlg $R_{\mathrm{L}}$ ) and analogRead $R_{\text {ph }}$ (anlg $R_{\text {ph }}$ ). These digital values are converted into voltages within in the range of $0-5 \mathrm{~V}$ which depends on the value of $V_{s}$. These digital values are converted into voltages within in the range of $0-5 \mathrm{~V}$ which depends on the value of $V_{s}$.

Based on 10 bit resolution calculated voltages are: voltage across $R_{\mathrm{L}}$ is $V_{\text {dig RL }}$ which is equal to ( $\left.\operatorname{anlg} R_{\mathrm{L}} \times V_{\mathrm{s}}\right) / 1023$, voltage across $R_{\text {ph }}$ is $V_{\text {dig Rph }}$ which is equal to (anlg $R_{\text {ph }} \times V_{\mathrm{s}}$ ) /1023.

Based on voltage dividing network calculated voltages are: voltage across $R_{\mathrm{ph}}$ is $V_{\mathrm{Rph}}$ which is equal to (anlg

Table $1 R_{\text {ph }}$ versus Int $\mathrm{l}_{\mathrm{x}}$ data from characteristic curve of LDR specification data sheet

\begin{tabular}{lccc}
\hline Intensity $(\mathrm{Ix})$ & $R_{\text {ph Mid }}(\Omega)$ & $R_{\text {ph Low }}(\Omega)$ & $R_{\text {ph Up }}(\Omega)$ \\
\hline 1 & 29,500 & 11,000 & 48,000 \\
2 & 25,000 & 16,000 & 34,000 \\
3 & 17,500 & 11,000 & 24,000 \\
4 & 13,000 & 8000 & 18,000 \\
5 & 11,400 & 6800 & 16,000 \\
6 & 10,000 & 6000 & 14,000 \\
7 & 9400 & 5800 & 13,000 \\
8 & 8750 & 5500 & 12,000 \\
9 & 8050 & 5100 & 11,000 \\
10 & 7400 & 4900 & 9900 \\
20 & 4950 & 4000 & 5900 \\
30 & 3600 & 3000 & 4200 \\
40 & 2900 & 2500 & 3300 \\
50 & 2650 & 2300 & 3000 \\
60 & 2325 & 1950 & 2700 \\
70 & 2175 & 1850 & 2500 \\
80 & 2100 & 1800 & 2400 \\
90 & 1900 & 1700 & 2100 \\
100 & 1825 & 1650 & 2000 \\
\hline
\end{tabular}

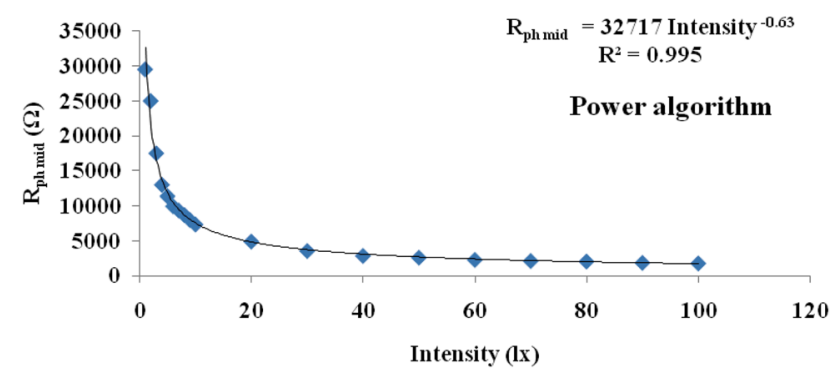

Fig. 1 Designed power algorithm using excel scattered and trend line analysis

$\left.R_{\mathrm{ph}} \times V_{\mathrm{s}}\right) /\left(\operatorname{anlg} R_{\mathrm{L}}+\operatorname{anlg} R_{\mathrm{ph}}\right)$, voltage across $R_{\mathrm{L}}$ is $V_{\mathrm{RL}}$ which is equal to (anlg $\left.R_{\mathrm{L}} \times V_{\mathrm{s}}\right) /\left(\operatorname{anlg} R_{\mathrm{L}}+\operatorname{anlg} R_{\mathrm{ph}}\right.$ ).

$R_{\mathrm{ph}}=\frac{R_{\mathrm{L}}}{\left(\frac{V_{\mathrm{s}}}{V_{\text {dig R ph }}}-1\right)}$.

$\operatorname{lnt}_{\mathrm{k} \mid \mathrm{x}}=\frac{\left(\frac{R_{\mathrm{ph}}}{32717}\right)^{\left(\frac{-1}{0.63}\right)}}{1000}$.

Optimization of CdS-LDR sensor is the conversion of photo-resistance $\left(R_{\mathrm{ph}}\right)$ of LDR sensor into projected intensity ${ }_{k \mid x}\left(\operatorname{lnt}_{\mathrm{k} \mid \mathrm{x}}\right)$ which is designed from its characteristic curve using power algorithm. Voltage across LDR sensor $\left(V_{\text {dig Rph }}\right)$ is converted into $R_{\text {ph }}$ of LDR sensor using Eq. (1). Equation (2) depicts the sunlight intensity measurement using optimized CdS-LDR sensor.

\subsection{Minimum dull intensity of the sunlight}

Without optimization, tracking mechanism is affected by LDR sensors, because LDR sensor can easily change its $R_{\text {ph }}$ with respect to intensity or illuminance of external light

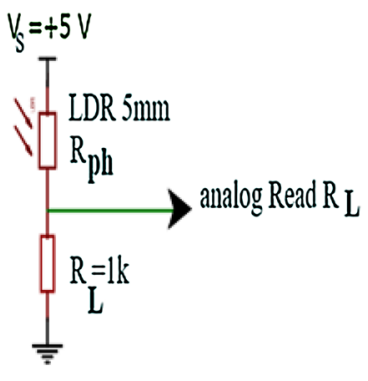

GND

(a)

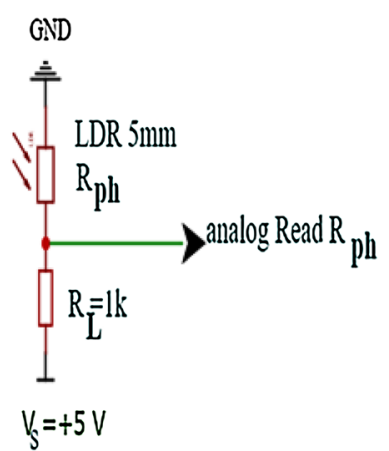

(b)

Fig. 2 a Measured analogRead $R_{\mathrm{L}}, \mathbf{b}$ measured analogRead $R_{\text {ph }}$ 
sources. Value of MDISL is nothing but the average intensity of the sunlight at minimum dark condition, which is measured by LDR sensor segment wise at the time of sunset or sunrise.

Here, MDISL represents the insufficient irradiance of the sun projected over the panel to generate the power during the time of sunrise, sunset and shading effect. It is used to stop the tracking to reduce the power consumption by tracking mechanism when there is insufficient irradiance of the sun. MDISL value is also used to place the solar panel to initial place.

At the time of sunset or sunrise the intensity of the sunlight (intensity $1000 \mathrm{~lx}$ is represented as $\operatorname{Int}_{\mathrm{kl}}$ ) is measured by optimized CdS-LDR sensor which is below $5 \mathrm{k}$ Ix and it's corresponding solar panel generated power is $0.027 \mathrm{~W}$. This power is insufficient to control the DAST system. The sun intensity value $5 \mathrm{k} I \mathrm{x}$ has been taken as MDISL value to be used to stop the tracking mechanism under insufficient or no irradiance of the sun as shown in Table 4.

\subsubsection{Initial position}

Without initial position condition, some generating power of solar panel is lost. The panel faces West side on previous day without initial position implementation which leads to shading effect on successive day due to nonuniform irradiance received by the solar panel. DASTsystem not captured the maximum irradiance on successive day without initial position implementation, because DAST system is existed under the partial shading effect until 9:00 to 9:30 AM as shown in Fig. 3.

This problem is also resolved by the parameter of MDISL with countdown time. Arduino 328p microcontroller prototype board provides software-based countdown time, without the need of external clock. On the previous day the solar panel is moved from East to West, after the sunset tracking mechanism is stopped by microcontroller which depends on the value of MDISL value. If the average value of MDSIL $\leq 5 \mathrm{k}$ Ix then the countdown time of microcontroller is immediately started. The panel is placed to initial

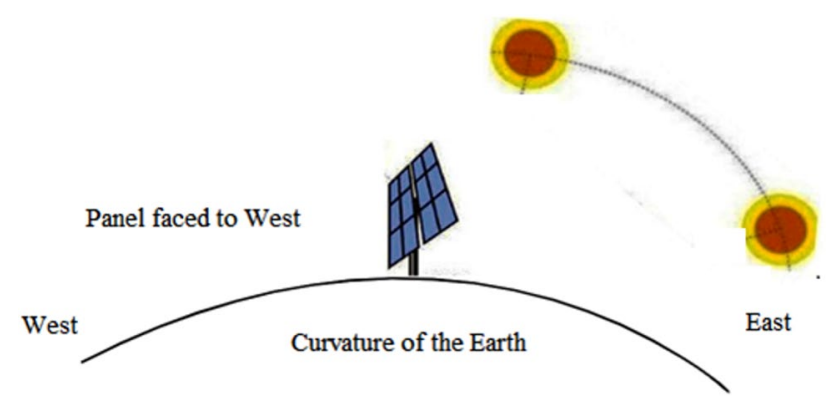

Fig. 3 Without initial position position immediately when it existed for more than $8 \mathrm{~h}$ of countdown time which depends on the value of MDISL as shown in Fig. 4.

Position $^{\circ} \Delta=$ Position ${ }^{\circ} \Delta+{ }^{\circ} \Delta H$.

Equation (3) is used to calculate total position degree change horizontally (Position ${ }^{\circ} \Delta$ ) with respect to degree of change horizontally $\left({ }^{\circ} \Delta H\right)$. Initial condition is implemented to horizontal movement of the tracking panel only, because on previous day it is observed that the panel surface directing towards the sunset which has total position degree change horizontally is $145^{\circ}-150^{\circ}$ and total position degree change vertically is $5^{\circ}-10^{\circ}$ with respect to the earth surface.

With initial condition, on successive day the panel is faced towards the direction of the sunrise which has total position degree change horizontally is $1^{\circ}-2^{\circ}$ and total position degree change vertically value is $5^{\circ}-10^{\circ}$. This small

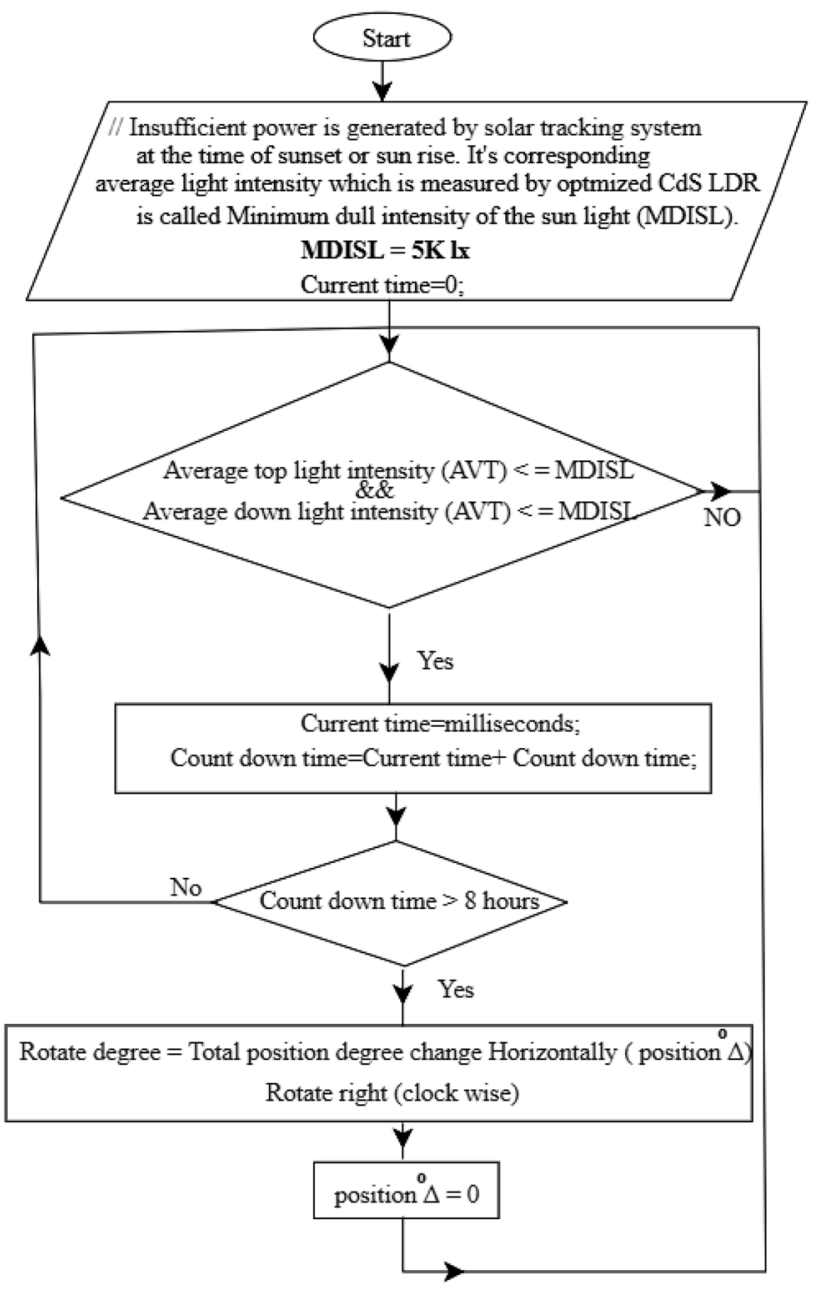

Fig. 4 Panel movement to initial place flow chart using minimum dull intensity of the sunlight 
degree change of horizontal and vertical movements is automatically controlled by microcontroller with optimized LDR sensors segment within 1-2 min. So vertical movement of the tracking system is not considered placing the panel to initial place. Total position degree change horizontally depends on curvature effect of the earth and initial installation position of the DAST system.

\subsection{Sudden switching cloud identification}

Air mass is another factor which changes the solar irradiance captured by solar panel, and air mass depends on the temperature and humidity values of the environmental condition. Actual air mass condition is not calculated in this experiment, whereas air mass is represented with THI [22] term.

$\mathrm{THI}=T_{\mathrm{F}}-\left(0.55-\left(0.55 \mathrm{R} \cdot \mathrm{H} \%\left(T_{\mathrm{F}}-58.8\right)\right)\right)$,

Here, $T_{\mathrm{F}}=1.8 T_{\mathrm{C}}+32$. Ambient temperature in Celsius $\left(T_{\mathrm{C}}\right)$, relative humidity in \% (R.H) and temperature in Fahrenheit $\left(T_{\mathrm{F}}\right)$ are used in Equation (4) to calculate THI .

It is observed that sudden high power impulses $\left(P_{\mathrm{H}_{\mathrm{I}}}\right)$ are generated with DAST system during the time of cloud effect, which are not observed throughout the day. These occurred at particular time instants only. These transients are due to sudden effect of sun rays during the time of effect of cloud, which look like sudden switching surges. Sudden cloud effect or cloud release is analyzed with $P_{\mathrm{HI}}$ with values of THI within 2-3s of short intervals of time.

$\mathrm{THI}_{\mathrm{C}}$ is represented as present THI value at $P_{\mathrm{H}}$, previous $\mathrm{THI}$ value is represented as $\mathrm{THI}_{\mathrm{p}}$, and next $\mathrm{THI}$ value is represented as $\mathrm{THI}_{N}$ which are shown in Fig. 5, where (1) value of $\mathrm{THI}_{\mathrm{P}}-\mathrm{THI}_{C}$ is increased and $\mathrm{THI}_{N}$ is equal to $\mathrm{THI}_{\mathrm{C}}$ which means the sun rays are released by the cloud. (2) Value of $\mathrm{THI}_{P}-\mathrm{THI}_{C}$ is decreased and $\mathrm{THI}_{N}$ is equal to $\mathrm{THI}_{C}$ which means the sun rays are effected by cloud. (3) Value of $\mathrm{THI}_{\mathrm{P}}-\mathrm{THI}_{\mathrm{N}}$ is constant and corresponding power increase or decrease which means the sun rays are immediate switching effect or release of cloud and vice versa.

\section{Design and implementations}

\subsection{Digital values reading in presence of sun intensity using CdS-LDR sensor using various connection types}

Data from Table 2, photo-resistance of LDR sensor anlg $R_{\text {ph }}$ (digital) value is very less at mid time in presence of the sun, whereas photo-resistance of anlg $R_{\mathrm{L}}$ which is high. This type of connection is indirect method to calculate anlg $R_{\mathrm{ph}}$, because microcontroller first reads the

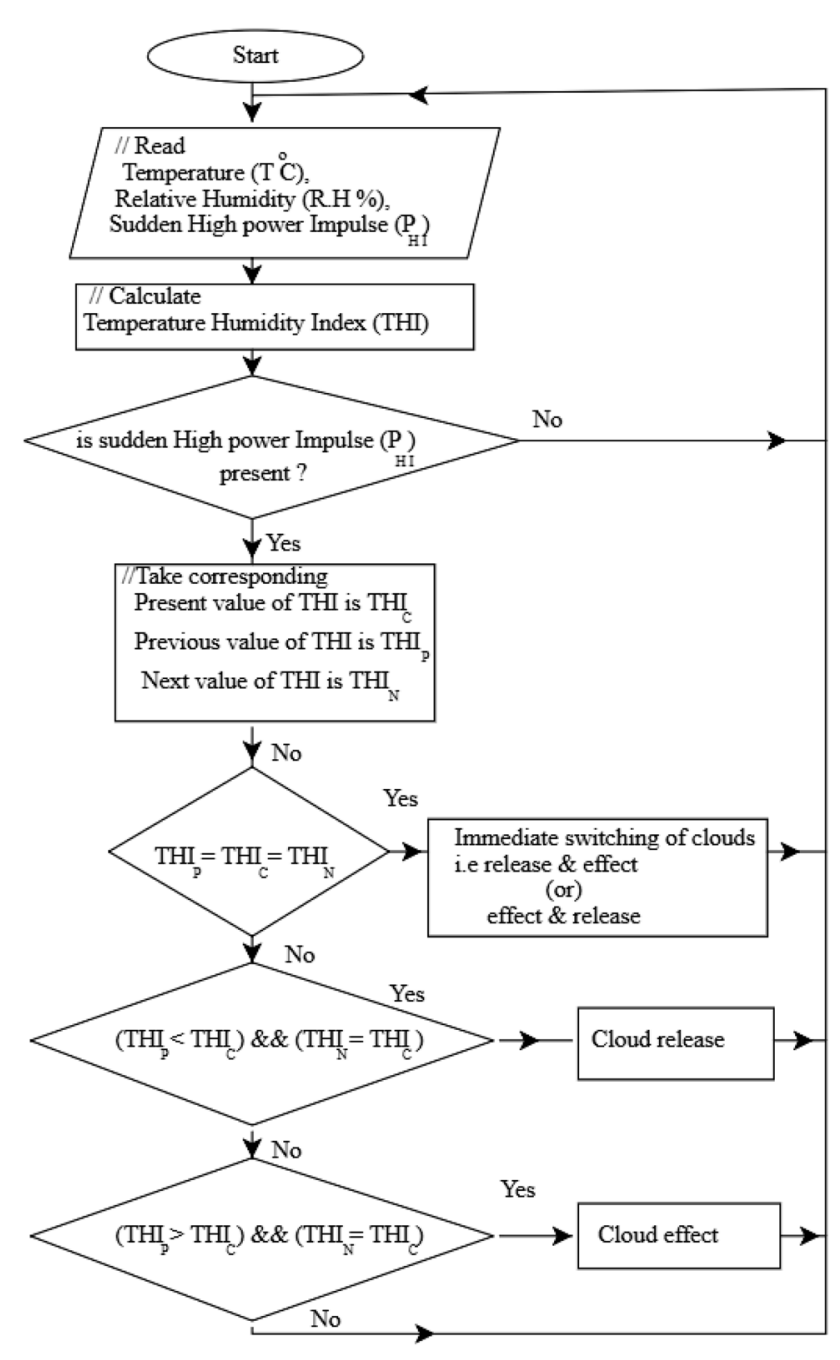

Fig. 5 Sudden switching of clouds

Table 2 Digital values in presence of the sun intensity when supply terminal is directly connected to LDR sensor

\begin{tabular}{lccll}
\hline Computer time & $\operatorname{anlg} R_{\mathrm{L}}$ & anlg $R_{\mathrm{ph}}$ & $V_{\mathrm{Rph}}(\mathrm{V})$ & $V_{\text {dig Rph }}(\mathrm{V})$ \\
\hline $11: 25: 47$ & 1015 & 8 & 0.04 & 0.04 \\
$11: 35: 19$ & 1012 & 11 & 0.06 & 0.05 \\
$11: 56: 25$ & 1010 & 14 & 0.07 & 0.07 \\
$12: 06: 08$ & 1014 & 10 & 0.05 & 0.05 \\
$12: 14: 30$ & 1012 & 12 & 0.06 & 0.06 \\
$12: 25: 48$ & 1010 & 13 & 0.06 & 0.06 \\
\hline
\end{tabular}

analog $R_{\mathrm{L}}$ which is further converted into anlg $R_{\mathrm{ph}}$. In this case anlg $R_{\text {ph }}=1023-\operatorname{anlg} R_{\mathrm{L}}$.

From Table 3, measured anlg $R_{\mathrm{ph}}$ is very less at mid time in presence of the sun, because intensity of the sun is large. This type of connection is direct method to calculate anlg $R_{\text {ph }}$, because microcontroller directly reads the anlg $R_{\mathrm{ph}}$. 
Table 3 Digital values in presence of the sun intensity when ground terminal is directly connected to LDR sensor

\begin{tabular}{llll}
\hline Computer time & anlg $R_{\text {ph }}$ & $V_{\text {R ph }}(\mathrm{V})$ & $V_{\text {dig Rph }}(\mathrm{V})$ \\
\hline 11:46:41 & 24 & 0.117 & 0.117 \\
11:46:58 & 23 & 0.110 & 0.110 \\
11:47:09 & 23 & 0.112 & 0.112 \\
$11: 47: 27$ & 24 & 0.115 & 0.115 \\
$11: 47: 35$ & 23 & 0.112 & 0.112 \\
$11: 47: 58$ & 23 & 0.110 & 0.110 \\
\hline
\end{tabular}

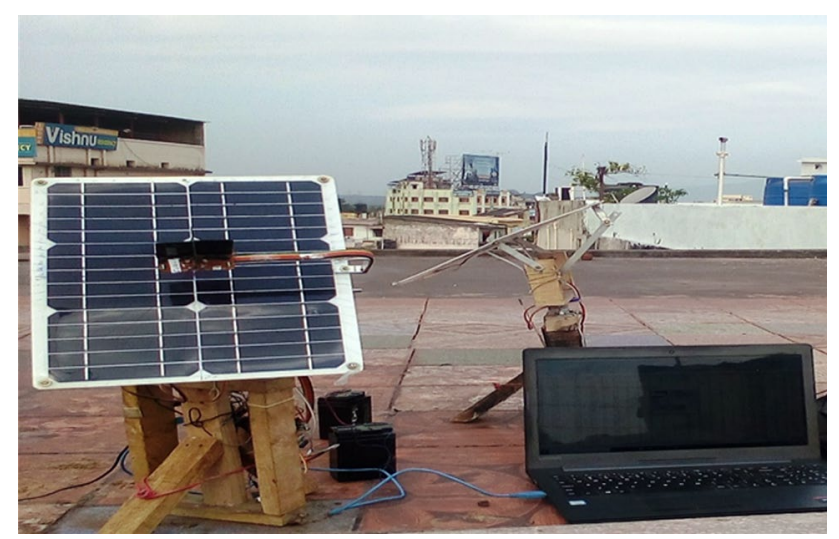

Fig. 6 Dual axis solar tracking system and fixed panel

From Tables 2 and 3, $V_{\text {dig Rph }}$ and $V_{\text {Rph. }}$ values are same, which means any type of connections as shown in Fig. 2 for voltage measurement across LDR sensor can be used.

The sunlight intensity measurement parameters using optimized CdS-LDR sensors are represented as left top light intensity (LT) of LDR in 1000 lux, right top light intensity (RT) of LDR in 1000 lux, left down light intensity (LD) of LDR in 1000 lux and right down light intensity (RD) of LDR in 1000 lux. Equation (2) is optimized CdS-LDR sensor equation which is used to implement the sunlight intensity measurement parameters like LT, RT, LD \& RD.

\subsection{Dual axis solar tracking system design}

DAST system along with fixed panel system is shown in Fig. 6. DAST system is a combination of active-based driver system and dual degree of freedom. Tracking mechanism is implemented with hybrid combination of stepper motor for horizontal movement of the solar panel and DC (Direct current) motor for vertical movement of the solar panel as shown in Fig. 7. Based on maximum annual average irradiance projected over the fixed panel at installed place, angle of fixed solar panel is fixed to $30^{\circ}$ using multiclinometer mobile application.

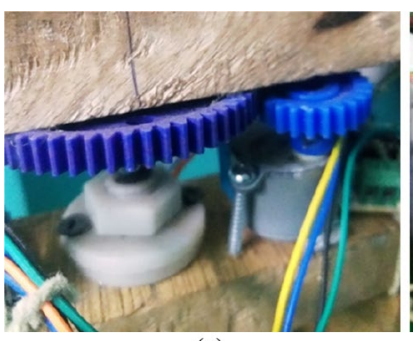

(a)

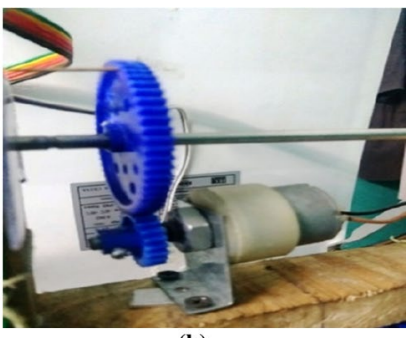

(b)
Fig. 7 a Stepper motor installation, b DC motor installation

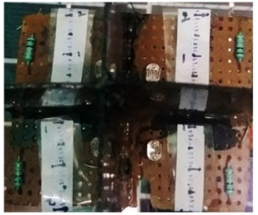

(a)

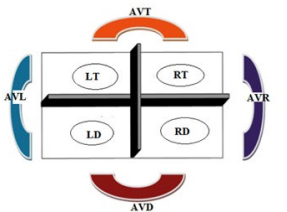

(b)

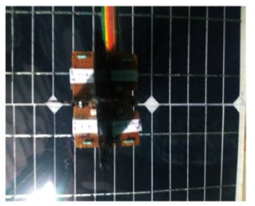

(c)
Fig. 8 a LDRs separated with 2-mm thick plastic black-coated material to minimize the light reflections or luminance, b Four quadrant LDRs structure segments wise representation, c LDRs position on the DAST system

Vertical movement of DAST system is controlled by DC motor which is rotated with fixed speed, constant voltage and low time interval mechanism. Vertical tracking control signals are passed to L293D dc motor driver which are operated with low time intervals of ON and OFF conditions by microcontroller. Horizontal movement of DAST system is controlled by $28 \mathrm{BYJ}-48$ unipolar stepper motor with 1 RPM (revolutions per minute) which has gearing ratio of 2075.77. Horizontal tracking control signals are passed to stepper motor driver (ULN 2003) by microcontroller.

Weight of solar panel is $300 \mathrm{~g}$. During vertical movement of the solar panel holding position (i.e., hold a position when there is no control signal from microcontroller) is unable to be controlled by using 28BYJ-48 unipolar stepper motor which has torque $0.08 \mathrm{~N}-\mathrm{m}$, though it consumes less power. 2KG (stp-43d1027-01) bipolar stepper motor which has holding torque of $0.314 \mathrm{~N}-\mathrm{m}$ is also unable to control the holding position, because gear wheel is directly connected to motor shaft as shown in Fig. 7b. Holding position is controlled by using 10 RPM geared DC motor which has rated torque of $0.687 \mathrm{~N}-\mathrm{m}$ and it requires less power consumption during tracking condition.

Two-millimeters thick plastic black-coated material is used to separate the reflections or luminance of the sun intensity projected from other sides of four quadrant LDR sensors segment wise structure as shown in Fig. $8 a$, b. LDR sensors segment structure is placed over the panel as shown in Fig. $8 \mathrm{c}$. 
Table 4 Minimum dull intensity of the sunlight (MDISL) value identification

\begin{tabular}{llllll}
\hline Computer time & AVR $(k \mid x)$ & AVL $(k \mid x)$ & AVT $(k \mid x)$ & AVD $(k \mid x)$ & $P(W)$ \\
\hline $6: 32: 00$ & 7 & 4 & 4 & 1 & 0.042 \\
$6: 32: 04$ & 7 & 4 & 5 & 2 & 0.042 \\
$17: 15: 59$ & 5 & 4 & 8 & 1 & 0.027 \\
$17: 16: 50$ & 4 & 3 & 6 & 1 & 0.021 \\
$17: 18: 41$ & 3 & 3 & 5 & 1 & 0.021 \\
$17: 20: 54$ & 2 & 2 & 4 & 0 & 0.027 \\
$17: 25: 52$ & 1 & 1 & 1 & 0 & 0.021 \\
$17: 28: 28$ & 1 & 0 & 1 & 0 & 0.024 \\
$17: 31: 51$ & 0 & 0 & 0 & 0 & 0.020 \\
\hline
\end{tabular}

Figure 15 describes the working flow of inputs and outputs which are interfaced by microcontroller. The execution of microcontroller is designed based on the multiple state machine concept which run all the inputs and outputs concurrently [23]. State machine concept minimizes the number of execution instructions which speed up the process of execution. Here, four CdS-LDR sensors are used to read light intensity using class file. In class file same instruction set is used to all four LDR sensors. Class file functioned like called function, but it is executed concurrently. Ambient temperature and humidity values are measured by using digital humidity temperature (DHT 11) sensor. Current sensor (ACS 712-05B) is used to measure the generated current from the solar panel, calibration of current sensor is tested to $0.0 \mathrm{~A}$ under open circuit condition as well as with known current values using power supply regulator. Voltage divider circuit is used to measure the generated voltage from the solar panel, calibration of voltage divider circuit is tested to $0.0 \mathrm{~V}$ under short circuit condition as well as with known current values using power supply regulator.

Vertical movement of optimized DAST system is controlled by microcontroller using the following parameters : average top light intensity (AVT), average down light intensity (AVD), top position (TP), bottom position (BP), and degree of change vertically $\left({ }^{\circ} \Delta \mathrm{V}\right)$.

AVT is equal to $(L T+R T) / 2$. AVD is equal to $(L D+R D) / 2$. TP is equal to mapping of (AVT, 0 to 500,0 to 100 ), BP is equal to mapping of (AVD, 0 to 500,0 to 100$),{ }^{\circ} \Delta \mathrm{V}$ is equal to mapping of (abs(TP-BP, 5 to $100,0.5^{\circ}$ to $\left.10^{\circ}\right)$ ).

Horizontal movement of optimized DAST system is controlled by microcontroller using the following parameters : average left light intensity (AVL), average right light intensity (AVR), left position (LP), right position (RP), and degree of change horizontally $\left({ }^{\circ} \Delta \mathrm{H}\right)$.

$A V L$ is equal to $(L T+L D) / 2$. AVR is equal to $(R T+R D) / 2$. $L P$ is equal to mapping of (AVL, 0 to 500,0 to 100). RP is equal to mapping of (AVR, 0 to 500,0 to 100 ). ${ }^{\circ} \Delta \mathrm{H}$ is equal to mapping of (abs(LP-RP, 5 to $100,2^{\circ}$ to $\left.10^{\circ}\right)$ ). Mapping technique is used to scale the calculated values into required range. Minimum $2^{\circ}$ is required to operate the stepper motor which is used in this experiment.

Experimental results are transferred from microcontroller to personal computer at 115200 baud rate using Universal Serial Bus (USB 2.0) cable. Results are stored in excel using PLX-DAQ excel macro-tool [24]. PLX-DAQ is a simple add-on Microsoft Excel tool which supports to collect each and every sample with in short interval of time to reduce the human effort in data collection process. Using PLX-DAQ errors can be minimized and accuracy of results is increased when more number of samples have been collected. More than 800 samples per hour of each data like average intensities of LDR sensors segment wise, degree change horizontally, degree change vertically, ambient temperature, relative humidity and power of solar panels are stored in excel using PLX-DAQ.

\section{Results and discussions}

\subsection{MDISL using optimized CdS-LDR sensor}

From Table 2 insufficient intensity of the light is projected over the panel which is identified using insufficient power generate by DAST. It is observed that $0.027 \mathrm{~W}$ of insufficient power is generated by solar panel. Corresponding segment wise measured average intensity of the sunlight is below $5 \mathrm{k}$ Ix using optimized CdS-LDR sensor (Table 4).

Overall day measured segment wise average intensities of the sun using optimized CdS-LDR sensors include cloud effect (from 7:57:39 to 11:08:30) at the same location on 7.12.2019 as shown in Fig. 9. It describes segment wise average intensities of the sun correlated in the same path. During the time of sunset, sunrise or cloudy condition segment wise average intensities of the sun using optimized CdS-LDR are more correlated with minimal difference of intensities.

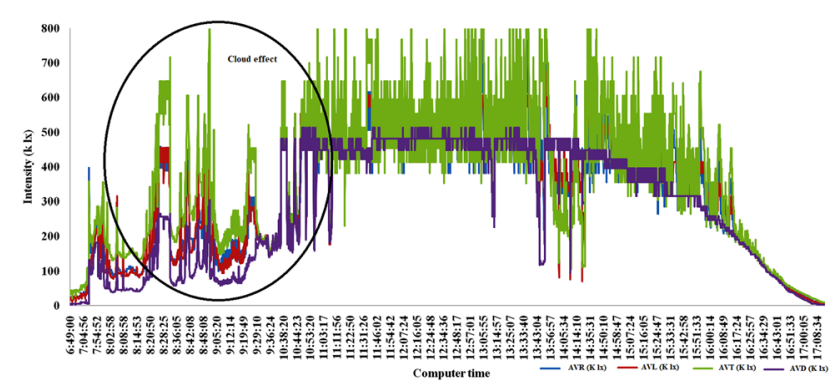

Fig. 9 Segment wise optimized average intensities of average top light intensity, average bottom light intensity, average left light intensity, and average right light intensity 
Data from Table 5, it is observed that before 6:32:00 and after 17:25:55 overall average intensity of the sunlight (AVG) using optimized CdS-LDR is zero. Intensity of the sun is very high during 11:27:41 to $15: 01: 23$. In the experiment value of MDISL using optimized CdS-LDR sensor is chosen at $5 \mathrm{k}$ Ix so that tracking of the system started at 6:32:04, and stopped before 6:32:04, because the intensity of the sun is less than $5 \mathrm{k} \mathrm{Ix}$. Tracking is again stopped at 17:15:59, at the same time countdown time is started which depends on the value of MDISL. After completion of $8 \mathrm{~h}$ of countdown time, panel is moved horizontally to initial place at 1:15:59 on successive day.

During countdown time, a $60 \mathrm{~W}$ bulb which illuminates $100 \mathrm{~lx}$ is projected over the LDR sensors segment perpendicularly and it does not affect the tracking mechanism, because its intensity value is below MDISL until it illuminates $5 \mathrm{k}$ Ix over the LDR sensors segment.

MDSIL designed with optimized CdS-LDR stops the tracking when there is insufficient intensity of the sunlight which minimizes the power consumption.

Overall average intensity of the sunlight (AVG) is equal to $(A V T+A V D+A V L+A V R) / 2$. Measured values of AVG (Ix) using optimized CdS-LDR with respect to $R_{\text {ph }}$ are shown in Fig. 10. During 6:32:00 to $17: 25: 55$, it is analyzed that intensity of the sunlight increases and corresponding $R_{\text {ph }}$ of the LDR sensor system decreases and vice versa. During the time of sunset and sunrise, value of $R_{\mathrm{ph}}$ is very large, because the intensity of the sunlight at that time is very less.

Table 5 Average intensity of the sunlight with respect to photoresistance of overall four structured LDR sensors

\begin{tabular}{lll}
\hline Computer time & AVG $(\mathrm{k} \mathrm{Ix})$ & $R_{\mathrm{ph}}(\Omega)$ \\
\hline $6: 32: 00$ & 5.5 & 174.50 \\
$6: 55: 07$ & 20 & 81.47 \\
$7: 10: 10$ & 37 & 56.67 \\
$7: 51: 54$ & 173.5 & 22.77 \\
$8: 00: 32$ & 129.5 & 27.06 \\
$9: 31: 23$ & 184.5 & 21.96 \\
$9: 42: 21$ & 197.75 & 21.08 \\
$10: 55: 52$ & 284.5 & 17.01 \\
$11: 27: 41$ & 480.75 & 12.48 \\
$12: 30: 48$ & 538 & 11.68 \\
$14: 51: 19$ & 508.5 & 12.08 \\
$15: 01: 23$ & 472 & 12.62 \\
$15: 30: 44$ & 348.5 & 15.09 \\
$16: 01: 58$ & 252.5 & 18.25 \\
$16: 29: 15$ & 153 & 24.53 \\
$16: 58: 06$ & 31.75 & 62.03 \\
$17: 25: 55$ & 0.75 & 565.36 \\
\hline & &
\end{tabular}

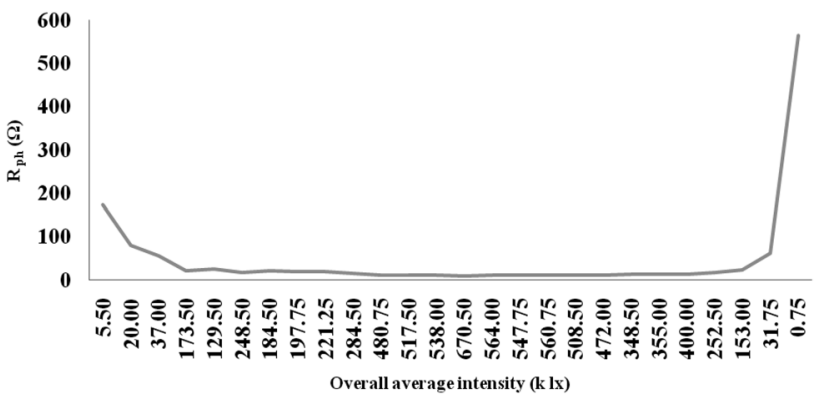

Fig. 10 Overall average photo-resistance of the optimized CdS-LDR sensor and overall average intensity in presence of the sunlight

\subsubsection{Analytical verification of Minimum dull intensity of the sunlight}

For justification of MDISL value, we considered the polynomial equation $y=f(x)=0.001 x^{5}-0.073 x^{4}+1.241 x^{3}-6.472 x^{2}+40.79 x-26.57$ which has $R^{2}$ value of 0.92 . Polynomial equation is correlated with the curve of average intensity of the sunlight AVG (Ix) and photo-resistance of the LDR sensor as shown Fig. 11. Where $x$ represents photo-resistance of the LDR sensor, $y$ represents average intensity $(\mathrm{k} \mid \mathrm{x})$ and their corresponding 1st derivative of $f(x)$ is $f(x)^{\prime}=d y / d x=0$ and 2nd derivative of $f(x)$ is $f(x)^{\prime}=(\mathrm{d} y / \mathrm{d} x)^{2}$ which are used to find analytical minimum condition of dull intensity of the sunlight. At $x_{1}=42.04512, f\left(x_{1}\right)^{\prime \prime}>0$ that is minimum dull intensity value starts at $R_{\mathrm{ph}}(\Omega)$ of LDR sensor is $42.045 \Omega$ in presence of the sunlight. In the proposed work MDISL is considered at $5 \mathrm{k} \mathrm{Ix}$ and its corresponding $R_{\mathrm{ph}}(\Omega)$ is approximately $174 \Omega$ which is more than $42.045 \Omega$, so we can justify that value of MDISL which is used to move the panel to initial place or to stop the tracking mechanism during dull light conditions. Analytically taken polynomial equation may change with change in curve as shown in Fig. 11.

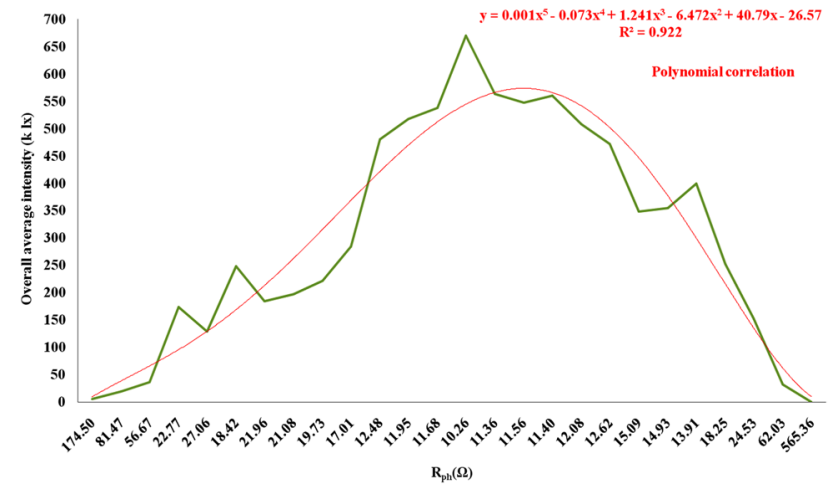

Fig. 11 Correlating the overall average intensity of the sun with photo-resistance 


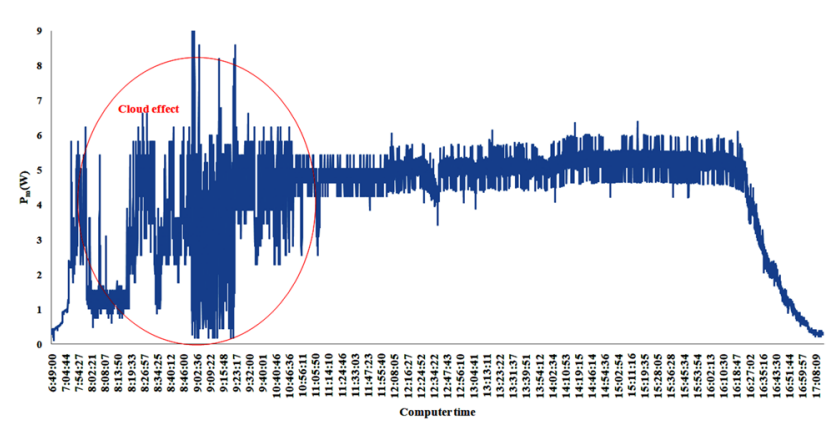

Fig. 12 Experimental performance of DAST system using optimized CdS-LDR throughout the day

\subsection{DAST system using optimized CdS-LDR}

Standard test conditions (STC) of solar panel used in the DAST application are: air mass (AM) is 1.5 , maximum peak power $\left(P_{\max }\right)$ is $15.00 \mathrm{~W}$ at irradiance $1000 \mathrm{~W} \mathrm{~m}^{-2}$ at $25^{\circ} \mathrm{C}$, maximum voltage $\left(V_{\text {pmax }}\right)$ is $17 \mathrm{~V}$, maximum peak current $\left(I_{\text {pmax }}\right)$ is $0.88 \mathrm{~A}$, total cell area is $0.0825 \mathrm{~m}^{2}$, cell efficiency of panel $\left(\eta_{\text {cell }} \%\right)$ is 18.18 , and temperature coefficient at $P_{\max }\left[\alpha p\left(\%{ }^{\circ} \mathrm{C}^{-1}\right)\right]$ is -0.44 . The experiment was conducted at latitude 17.711521 longitude 83.299172 on 7.12.2019 from 6:32:00 to $17: 40: 15$ in Visakhapatnam, Andhra Pradesh. Global irradiance (Ir) data are taken from India Meteorological Department database which is measured at station 43150 . Ir value is used to calculate the theoretical values of solar panel cell input power $\left(P_{\text {in }}\right)$. Change in temperature $\left(\Delta T_{\mathrm{c}}\right)$ will also affect the efficiency of generated solar panel power. Solar panel output power with $\Delta T_{c}$ is theoretically calculated $\left(P_{\text {out }}\right)$ using Eq. (5).

$P_{\text {out }}=\left[1+\triangle T_{\mathrm{c}} \times \alpha_{\mathrm{p}} \%\right] \times P_{\text {in }} \times \eta_{\text {cell }} \%$,

where $P_{\mathrm{i}}=\operatorname{Ir} \times$ Total cell area, $\Delta T_{\mathrm{c}}=T_{\mathrm{STC}}-T_{\mathrm{m}} T_{\mathrm{m}}$ is measured average temperature and $T_{\text {STC }}$ is standard test condition temperature of the solar panel which is equal to $25^{\circ} \mathrm{C}$.

Figure 12 depicts the experimental performance of DAST system using optimized CdS-LDR throughout the day include and exclude cloud effects are discussed in Sects. 4.2.1, 4.2.2, and 4.2.3.

\subsubsection{Experimental and theoretical performance of DAST system using optimized CdS-LDR throughout the day}

The results are carried out at the same location on 7.12.2019 from 6:49:00 to 17:14:27. Studies are carried out to observe the overall performance of optimized DAST system. Measured value is analyzed with the theoretical value as shown in Table 6.
Table 6 Day performance of DAST system include cloud effect, i.e., from 6:49:00 to17:14:27

\begin{tabular}{lllllll}
\hline $\operatorname{Ir}\left(\mathrm{W} \mathrm{m}^{-2}\right)$ & \multicolumn{2}{l}{ Measured } & & \multicolumn{3}{l}{ Theoretical } \\
\cline { 2 - 3 } \cline { 6 - 7 } & $P_{\mathrm{m}}(\mathrm{W})$ & $T_{\mathrm{m}}\left({ }^{\circ} \mathrm{C}\right)$ & & $P_{\text {in }}(\mathrm{W})$ & $\Delta T_{\mathrm{c}}$ & $P_{\text {out }}(\mathrm{W})$ \\
\hline 445.83 & 4.12 & 31.18 & & 36.78 & -6.18 & 6.87 \\
\hline
\end{tabular}

Table 7 Performance of DAST system during the time of effect of clouds, i.e., from 7:57:39 to 11:08:30

\begin{tabular}{lllllll}
\hline $\operatorname{Ir}\left(\mathrm{W} \mathrm{m}^{-2}\right)$ & \multicolumn{2}{l}{ Measured } & & \multicolumn{3}{l}{ Theoretical } \\
\cline { 2 - 3 } \cline { 6 - 7 } & $P_{\mathrm{m}}(\mathrm{W})$ & $T_{\mathrm{m}}\left({ }^{\circ} \mathrm{C}\right)$ & & $P_{\text {in }}(\mathrm{W})$ & $\Delta T_{\mathrm{c}}$ & $P_{\text {out }}(\mathrm{W})$ \\
\hline 264.84 & 3.49 & 28.75 & & 21.85 & -3.75 & 4.04 \\
\hline
\end{tabular}

Table 8 Performance of DAST system exclude cloud condition, i.e., from 11:03:39 to15:52:45

\begin{tabular}{lllllll}
\hline $\operatorname{Ir}\left(\mathrm{W} \mathrm{m}^{-2}\right)$ & \multicolumn{2}{l}{ Measured } & & \multicolumn{3}{l}{ Theoretical } \\
\cline { 2 - 3 } & $P_{\mathrm{m}}(\mathrm{W})$ & $T_{\mathrm{m}}\left({ }^{\circ} \mathrm{C}\right)$ & & $P_{\text {in }}(\mathrm{W})$ & $\Delta T_{\mathrm{c}}$ & $P_{\text {out }}(\mathrm{W})$ \\
\hline 590.28 & 5.05 & 33.74 & & 48.70 & -8.74 & 9.19 \\
\hline
\end{tabular}

Theoretically calculated power $\left(P_{\text {out }}\right)$ is $6.87 \mathrm{~W}$, measured average power $\left(P_{\mathrm{m}}\right)$ is $4.12 \mathrm{~W}$. Ratio of $P_{\mathrm{m}}$ to $P_{\text {out }}$ is expressed as EXP ${ }_{\text {out }}$. Day performance of the system include cloud effect ( $\mathrm{EXP}_{\text {out }}$ ) is $59.92 \%$ of the theoretically calculated value.

\subsubsection{Experimental and theoretical performance of DAST system using optimized CdS-LDR during cloudy}

The effect of cloud changes the irradiance of the sun projected over the surface of the solar panel Which is observed during 7:57:39 to 11:08:30. Cloud effect leads to either change of position or staying at the current position which depends on the MDISL. The measured average power $P_{\mathrm{m}}(\mathrm{W})$ is compared against theoretical value of $P_{\text {out }}$ as shown in Table 7.

Theoretically calculated solar panel out power $\left(P_{\text {out }}\right)$ is $4.04 \mathrm{~W}$, measured average power $\left(P_{\mathrm{m}}\right)$ is $3.49 \mathrm{~W}$. Performance of optimized DAST system during the time of cloudy ( $\left.\mathrm{EXP}_{\text {out }}\right)$ is $86.49 \%$ of the theoretically calculated value.

\subsubsection{Experimental and theoretical performance of DAST system using optimized CdS-LDR exclude cloudy}

Cloud effects completely released the sunlight during the time of 11:03:39-15:52:45. Theoretically calculated solar panel out power $\left(P_{\text {out }}\right)$ is $9.19 \mathrm{~W}$, measured average power $\left(P_{\mathrm{m}}\right)$ is $5.05 \mathrm{~W}$. Performance of optimized DAST system 


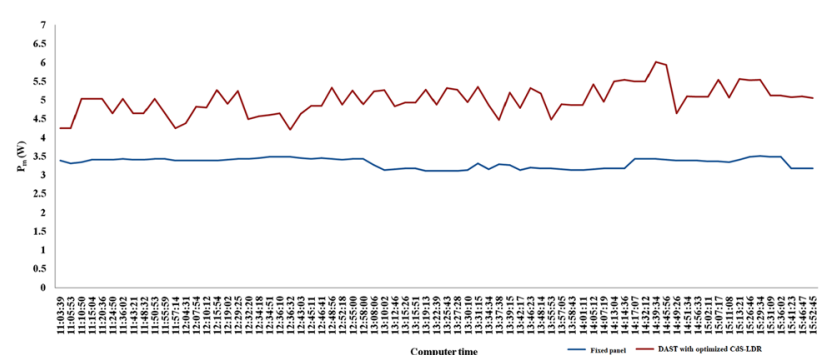

Fig. 13 Measured power of fixed panel and DAST system using optimized CdS-LDR without cloudy condition

during the time of cloudy $\left(\mathrm{EXP}_{\text {out }}\right)$ is $54.88 \%$ of the theoretically calculated value (Table 8 ).

Using optimized CdS-LDR sensors in the application of DAST system $86.49 \%$ of power is generated during the time of cloudy condition, $54.88 \%$ of power is generated exclude cloud condition, and $59.92 \%$ of power is generated throughout the day with reference to theoretical values. During cloudy $31.61 \%$ of more power is generated by DAST system which means optimization of CdS-LDR as the sun-pointing sensor increases the tracking accuracy.

\subsection{Performance comparison of DAST system using optimized CdS-LDR sensor with fixed panel}

Generated average power of optimized DAST system $\left(P_{\text {DAST }}\right)$ during the time of 11:03:39 to $15: 52: 45$ is $5 \mathrm{~W}$, whereas generated average power of the fixed panel $\left(P_{\text {Fixed }}\right)$ is $3.32 \mathrm{~W}$ under clear sky conditions as shown in Fig. $13.50 .63 \%$ of power is gained with reference to fixed panel. In addition to that improvements of current work with other existing works are described in Table 9.

Present work implemented with intensity of the sunlight as control parameter in DAST system using optimized CdSLDR sensor include MDISL method performed better than the recently existing works which are designed based on Arduino microcontroller with control parameters like analog signal5 [13] or voltage signal [19].

Table 9 Power gain of DAST systems with reference to fixed panel

\begin{tabular}{lll}
\hline Control parameter & Sun-pointing sensor & Power gain (\%) \\
\hline [16], Voltage & LDR + AVR & 29.78 \\
[17], Voltage & LDR + PLC & $30-40$ \\
[18], Analog & LDR + AVR & 28.04 \\
[15], Voltage & LDR + Arduino & $25-30$ \\
[19], Voltage & LDR + Arduino & $30-40$ \\
[13], Analog & LDR + Arduino & 36.25 \\
\hline
\end{tabular}

Table 10 Effect and release of cloud conditions using sudden high power impulses with reference to $\mathrm{THI}$

\begin{tabular}{|c|c|c|c|c|}
\hline Computer time & $P_{\mathrm{m}}(\mathrm{W})$ & $T_{\mathrm{m}}\left({ }^{\circ} \mathrm{C}\right)$ & R.H (\%) & THI \\
\hline 8:26:30 & 5.432 & 27 & 76 & $89.162(P)$ \\
\hline 8:26:32 & $6.621(\mathrm{HI})$ & 28 & 77 & $91.845(\mathrm{C})$ \\
\hline 8:26:35 & 5.432 & 28 & 77 & $91.845(\mathrm{~N})$ \\
\hline $8: 26: 47$ & 4.639 & 28 & 77 & $91.845(P)$ \\
\hline $8: 26: 50$ & $6.225(\mathrm{HI})$ & 28 & 76 & $91.715(\mathrm{C})$ \\
\hline 8:26:52 & 5.432 & 28 & 76 & $91.715(\mathrm{~N})$ \\
\hline $8: 28: 23$ & 4.639 & 29 & 73 & 93.848 \\
\hline $8: 28: 25$ & $6.621(\mathrm{HI})$ & 29 & 73 & $93.848(C)$ \\
\hline $8: 28: 28$ & 3.847 & 29 & 73 & 93.848 \\
\hline 8:28:30 & $5.432(\mathrm{HI})$ & 29 & 73 & $93.848(\mathrm{C})$ \\
\hline 8:54:34 & 4.639 & 28 & 77 & 91.845 \\
\hline 8:54:37 & 6.621 & 28 & 77 & 91.845 \\
\hline 8:54:40 & $9.791(\mathrm{HI})$ & 28 & 77 & $91.845(\mathrm{C})$ \\
\hline 8:54:42 & 7.413 & 28 & 77 & 91.845 \\
\hline 8:54:45 & $7.809(\mathrm{HI})$ & 28 & 77 & $91.845(\mathrm{C})$ \\
\hline 8:54:48 & 5.432 & 28 & 77 & 91.845 \\
\hline 8:54:50 & $5.432(\mathrm{HI})$ & 28 & 77 & $91.845(\mathrm{C})$ \\
\hline 8:55:35 & 9.395 & 28 & 76 & 91.715 \\
\hline $8: 55: 38$ & $5.828(\mathrm{HI})$ & 28 & 75 & $91.585(\mathrm{C})$ \\
\hline 8:55:40 & 8.206 & 28 & 75 & 91.585 \\
\hline 9:03:47 & 5.471 & 27 & 79 & 89.522 \\
\hline 9:03:49 & $6.225(\mathrm{HI})$ & 27 & 79 & $89.522(\mathrm{C})$ \\
\hline 9:03:53 & 7.413 & 27 & 79 & 89.522 \\
\hline 9:03:57 & 6.225 & 27 & 79 & 89.522 \\
\hline 9:04:00 & $8.602(\mathrm{HI})$ & 27 & 79 & $89.522(C)$ \\
\hline 9:04:03 & 5.432 & 27 & 79 & 89.522 \\
\hline
\end{tabular}

\subsection{Sudden switching cloud effect or cloud release}

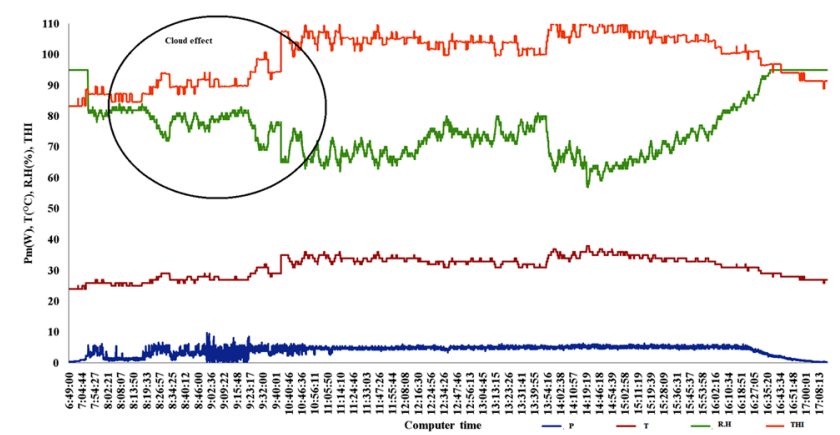

Fig. $14 \mathrm{THI}, P_{\mathrm{m}}(\mathrm{W}), T\left({ }^{\circ} \mathrm{C}\right)$, and $\mathrm{R} . \mathrm{H}(\%)$ curves during the time of effect of clouds

\section{during short interval of time}

Additional outcome during the experimental process of DAST system using optimized CdS-LDR sensor is observed to identify the cloudy condition as shown in Table 10 . Images are taken during the time of cloud effect as shown in Fig. 16. The density of the clouds is referred with the 


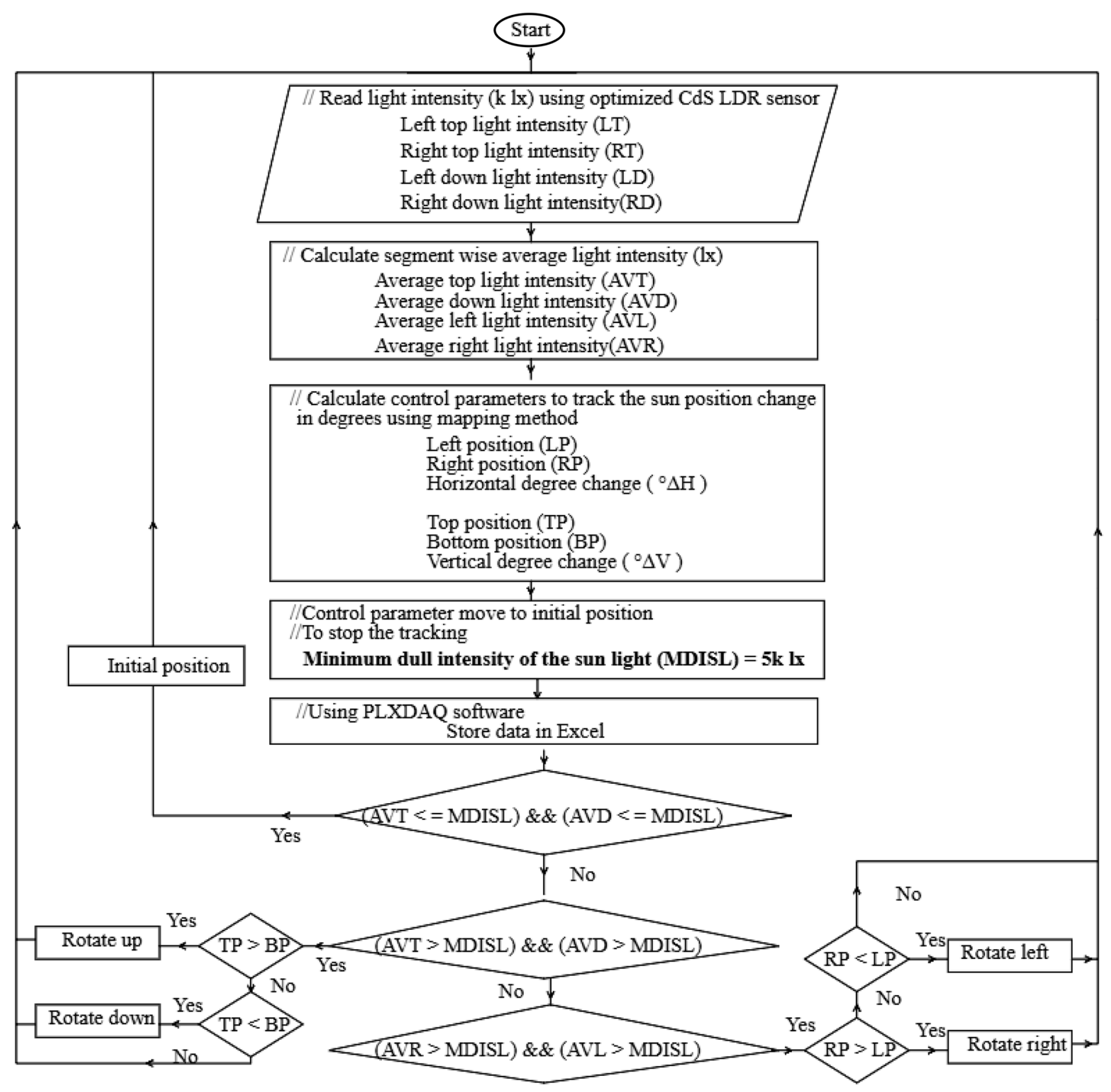

Fig. 15 Working flow chart

generated sudden high power impulses of DAST system using optimized CdS-LDR sensor which are shown in each image. The generated power of DAST system using optimized CdS-LDR depends on the irradiance incident on the surface of the solar panel.

THI value is taken to analyze the switching effects during short interval of time such as,

(a) From 8:26:30 to 8:26:40 AM, cloud released the sun rays. Sudden switching reference high power impulse $\left(P_{\mathrm{HI}}\right)$ is $6.621 \mathrm{~W}$ and its corresponding $\mathrm{THI}_{\mathrm{C}}$ value is 91.84 , this case is represented as a very small density cloud effect released, another example is 9:22:23 to 9:22:28 AM.

(b) From 8:26:47 to 8:26:52 AM, cloud effected the sun rays. $P_{\mathrm{HI}}$ is $6.225 \mathrm{~W}$ and $\mathrm{THI}_{\mathrm{C}}$ value is 91.715 , this case is represented as switching into cloud effect, another examples are 8:55:35-8:55:40 AM, 9:22:51-9:23:02 AM.

(c) From 8:28:23 to 8:28:30 AM, released and immediately effected the sun rays. $P_{\mathrm{HI}}$ values are $6.620 \mathrm{~W}, 5.431$ $\mathrm{W}$ and their corresponding $\mathrm{THI}_{\mathrm{C}}$ values are 93.848 and 93.848. This case is considered as immediate switching of effect-release of cloud, because their corresponding 


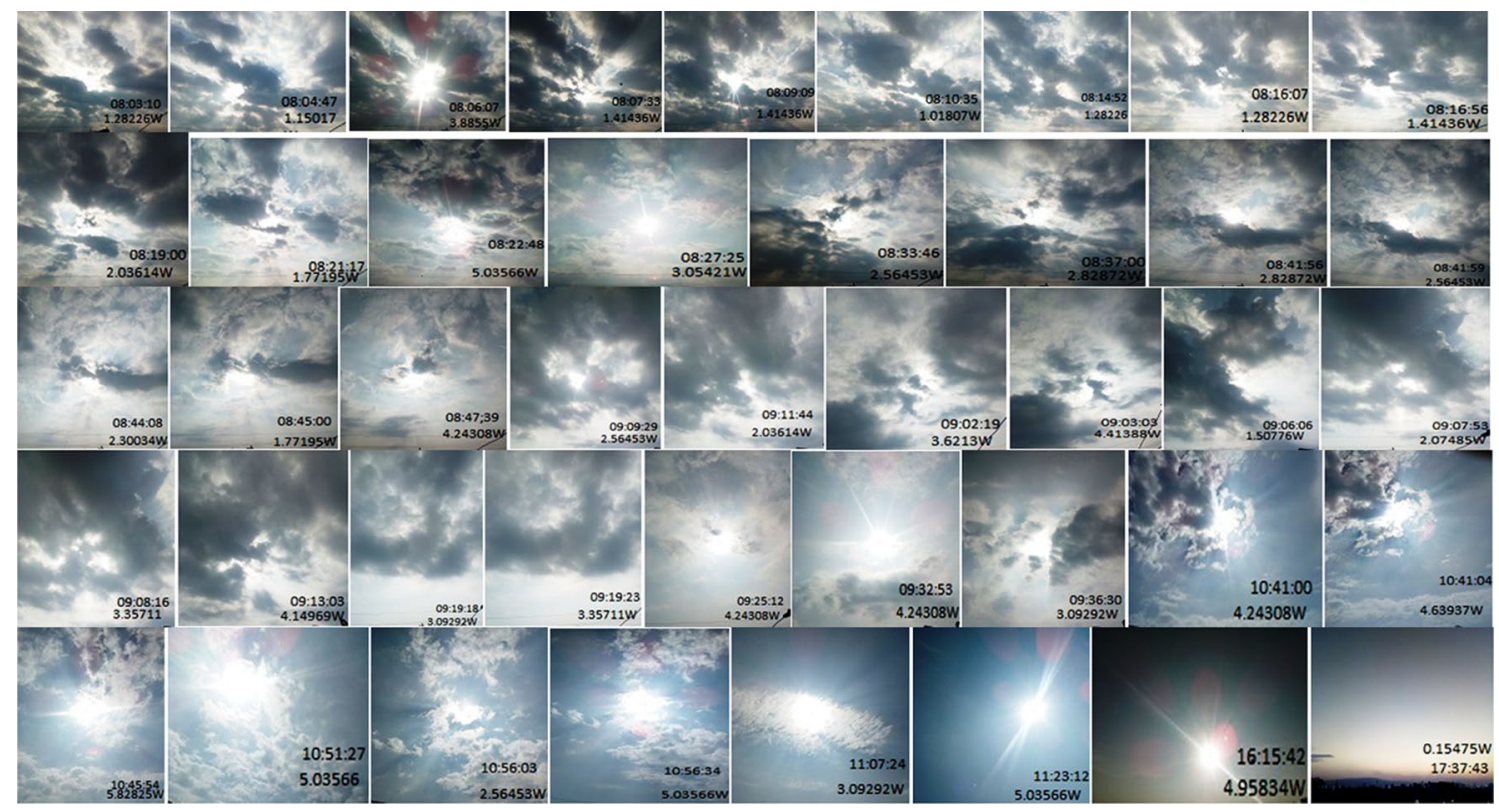

Fig. 16 Cloud effect images captured from 7:57:39 to 11:08:30 AM and it's corresponding generated power by DAST using optimized CdSLDR sensor

powers are decreased and then increased, another examples are 9:03:57-9:04:11 AM, 9:13:50-9:14:09 AM.

(d) From 8:54:34 to 8:54:45 AM, there is a random effect and release of the sun rays by the clouds within short interval of time, sudden switching reference high power impulses are $9.79115 \mathrm{~W}, 7.8097 \mathrm{~W}, 5.43196 \mathrm{~W}$. In all above cases types of cloud are not mentioned.

It is also analyzed that THI curve is proportional to temperature curve and inversely proportional to relative humidity curve with some scaled factor as shown in Fig. 14.

Climatic factors such as air temperature, humidity, rainfall, amount of clouds and dust density are negatively affecting the technical performance of the solar panel [25].

Slippage error in terms of degree is encountered during downward movement of DAST system controlled by geared DC motor. If the size of the solar panel increases more torque is needed with less RPM (revolutions per minute). Low RPM geared DC motor is needed to hold the vertical position of the solar panel.

\section{Conclusion}

Optimized CdS-LDR sensors with intensity parameter using power algorithm which is performed include cloud effects for the application of DAST system. Performance of the optimized DAST is $86.49 \%$ of theoretically observed value during the time of cloud conditions. With optimized DAST system gained power is $48-52 \%$ with reference to fixed panel. This value is further changed if the energy consumption of tracking motors is also considered. Increase or decrease in percentage of generated power of solar panel is due to abnormalities of the irradiance and temperature. Minimum dull intensity of the sunlight is another key factor to place the panel in initial position. For more accuracy, the overall day performance of DAST system is analyzed with collected data of 8800 samples of each parameter. Transients of cloud effect are analyzed by more data collection within short interval of time which is done by PLX-DAQ tool. Results may change when experiment is conducted under greater exposure of wind speed or heavy rain condition. Still, there is some misalignment angle along with the direction of top segment and bottom segment of LDR sensor due to effect of jerks during vertical tracking by DC motor. Jerking occurs due to loading effect of improper fixing. It is observed that still the experiment still lacks attaining 100\% accuracy because of misalignment angle, and altitude value in theoretical solar panel output power calculation is neglected in this design aspect. Design and development of irradiance sensor using optimized CdS-LDR sensor is our future work. It can be achieved by intensity of the sunlight data validated with irradiation measured by standard equipment.

\section{Compliance with ethical standards}

Conflict of interest On behalf of all authors, the corresponding author states that there is no conflict of interest. 


\section{References}

1. Carrasco M et al (2017) Low-cost solar irradiance sensing for PV systems. Energies. https://doi.org/10.3390/en10070998

2. Salgado-Conrado $L$ (2018) A review on sun position sensors used in solar applications. Renew Sustain Energy Rev 82:21282146. https://doi.org/10.1016/j.rser.2017.08.040

3. Sai $Y$ et al (2011) Advanced research on computer science and information Engineering. Springer, Berlin, pp 8-14

4. Samanta A et al (2012) A simple and efficient sun tracking mechanism using programmable logic controller. Sol Energy Conc. https://doi.org/10.3103/S0003701X12030140

5. Tina GM et al (2012) Intelligent sun-tracking system based on multiple photodiode sensors for maximisation of photovoltaic energy production. Math Comput Simul. https://doi. org/10.1016/j.matcom.2012.07.020

6. Wang JM et al (2013) Design and implementation of a sun tracker with a dual-axis single motor for an optical sensor-based photovoltaic system. Sensors 13(3):3157-3168

7. Wang $\mathrm{H}$ et al (2014) A self-powered single-axis maximum power direction tracking system with an on-chip sensor. Sol Energy. https://doi.org/10.1016/j.solener.2014.11.019

8. Garrido R et al (2016) Cascade closed-loop control of solar trackers applied to HCPV systems. Renew Energy. https://doi. org/10.1016/j.renene.2016.06.022

9. Fazlizan A, Abdulmula A et al (2018) Performance evaluation of maximum light detection solar tracking system in the tropics. J Mech Sci Technol. https://doi.org/10.1007/s1220 6-019-0240-2

10. Morón C, Ferrández D et al (2017) New prototype of photovoltaic solar tracker based on Arduino. Energies. https://doi. org/10.3390/en 10091298

11. Away Y et al (2016) Dual-axis sun tracker sensor based on tetrahedron geometry. Autom Constr. https://doi.org/10.1016/j. autcon.2016.10.009

12. Gama A et al (2013) Design and realization of a novel sun tracking system with absorber displacement for parabolic trough collectors. J Renew Sustain Energy 10(1063/1):4807476

13. Hammoumi AE, Motahhir S (2018) A simple and low-cost active dual-axis solar tracker. Energy Sci Eng. https://doi.org/10.1002/ ese3.236

14. Motahhir S, Hammoumi AE (2019) Open hardware/software test bench for solar tracker with virtual instrumentation.
Sustain Energy Technol Assess. https://doi.org/10.1016/j. seta.2018.11.003

15. Akbar HS (2017) Microcontroller based dual axis sun tracking system for maximum solar energy generation. Am J Energy Res. https://doi.org/10.12691/ajer-5-1-3

16. Rahman $S$ et al (2013) Design \& implementation of a dual axis solar tracking system. Am Acad Sch Res J 5(1):47-54

17. Assaf EM (2014) Design and implementation of a two axis solar tracking system using PLC techniques by an inexpensive method. Int J Acad Sci Res 2(3):54-65

18. Ferdaus RA, Mohammed MA, Rahman S et al (2014) Energy efficient hybrid dual axis solar tracking system. J Renew Energy. https://doi.org/10.1155/2014/629717

19. Bharati $M$ et al (2017) Solar power tracking system and power saving in highway street light. Int J Innov Res Comput Commun Eng 5(4):276-285

20. Zaiontz C (2012-2019) Real statistics using excel. http://www. real-statistics.com/regression/power-regression/. Accessed 2019

21. Brown AM (2001) A step-by-step guide to non-linear regression analysis of experimental data using a Microsoft Excel spreadsheet. Comput Methods Programs Biomed 65(3):191-200. https ://doi.org/10.1016/S0169-2607(00)00124-3

22. Vlăduţ $A$ (2011) Temperature-Humidity Index (THI) within the Oltenia Plain between 2000 and 2009. Forum Geografic. https ://doi.org/10.5775/fg.2067-4635.2011.033.i

23. Earl B et al (2014) Multi tasking the Arduino. https://learn.adafr uit.com/multi-tasking-the-arduino-part-1/all-together-now. Accessed 2014

24. Hammoumi E et al (2018) Low-cost virtual instrumentation of PV panel characteristics using Excel and Arduino in comparison with traditional instrumentation. Renew Wind Water Sol. https ://doi.org/10.1186/s40807-018-0049-0

25. Kang $\mathrm{H}$ et al (2019) Technical performance analysis of the smart solar photovoltaic blinds based on the solar tracking methods considering the climate factors. Energy Build. https://doi. org/10.1016/j.enbuild.2019.02.013

Publisher's Note Springer Nature remains neutral with regard to jurisdictional claims in published maps and institutional affiliations. 